\title{
An Analysis of Herding Behaviour during Market Cycles in South Africa
}

\author{
*Yudhvir Seetharam, James Britten \\ University of the Witwatersrand Johannesburg, South Africa \\ *yudhvir.seetharam@wits.ac.za
}

\begin{abstract}
Herding behaviour can be captured by the relationship between share price movements with the market, typified by beta. We examine herding behaviour for the period 1995 to 2011 and find that it is absent overall, yet present during bear market periods only. When examined alongside the market cycle, herding appears to dramatically fluctuate before a market contraction. Conceptually, herding can be seen as an explanatory factor for the existence of a nonlinear market model. Our findings infer that a negative market reaction (contraction) is preceded by an increase in herding. The evidence of herding in during a South African market contraction can thus impact financial forecasts and volatility estimates of the market. Further, it could possibly indicate the level of confidence of market participants - both experienced and inexperienced individuals tend to follow the group consensus in times of a market downturn, yet deviate from the group consensus in times of a market upturn.
\end{abstract}

Keywords: Market Structure and Pricing, Analysis of Collective Decision-Making, Information, Knowledge and Uncertainty, General Financial Markets

\section{Introduction}

"Human behaviour is a main factor in how markets act. Indeed, sometimes markets act quickly, violently with little warning. Ultimately, history tells us that there will be a correction of some significant dimension. I have no doubt that, human nature being what it is, that it is going to happen again and again." "Financial research has begun to incorporate human behaviour in describing the actions of financial markets. It seems appropriate to account for an investor's thoughts, emotions and actions rather than assume that there is an idealised investor, who acts rationally at every point in time and whose behaviour provides the foundations for efficient markets. Behavioural finance has received increased attention over the last decade as current finance theory was deemed by most to be inadequate in explaining various anomalies and market crashes. This area of finance combines psychology and sociology to explain investor behaviour, arguably providing a more holistic theoretical basis for financial decision making. Of the various behavioural theories, this paper examines herding behaviour alongside market cycles (an idea first proposed by Lux, 1995) in South Africa. Herding is examined via a relative measure (through time) and is "superimposed" with the market cycle to hypothesise any behaviour detected. Herding behaviour can be described as a mimicking of actions by investors. It is generally believed to be a critical element of investor behaviour in financial markets, yet little empirical evidence exists in its favour. Herding behaviour can be due to a variety of reasons, the most common being that of irrationality ${ }^{2}$. However, herding may also be detected through a rational reaction to changes in fundamentals. The former reason potentially implies market inefficiency whilst the latter implies an efficient reallocation of assets. Herding behaviour can be exhibited by individual and collective investors (such as mutual funds). The reader may find a conceptual similarity between correlation or clustering of share returns and herding behaviour. This "clustering" forms the basis for the first two methods of detecting herding behaviour - namely, the dispersion of returns (Christie and Huang, 1995) and the nonlinearity of dispersion (Chang, Cheng and Khorana, 2000). These two tests examine herding in a linear and non-linear form, respectively.

\footnotetext{
${ }^{1}$ Alan Greenspan, former Chairman of the Federal Reserve of the USA, before the Committee on Banking and Financial Services, US House of Representatives, 24 July 1998.

${ }^{2}$ We use the term "irrational" to refer to the market instead of the individual, where the market is simply the aggregate of all participants within it. There may well be situations in which it may be rational for an investor to follow the crowd. This behavior, however, may lead to inefficient asset prices and hence irrational market behavior.
} 
A shortcoming suffered by both these tests is that they look for the presence of herding over the entire sample period. So, hypothetically, if herding did exist at a point in the sample period, it may not have been prominent enough to imply significance over the entire period. Thus, herding would need to be examined relative to periods of time. We employ the beta coefficient test (Hwang and Salmon, 2001) in this regard. This test views herding in a relative sense as opposed to an absolute one (as with the first two tests) and is the preferred measure in our study. The beta coefficient test, based on movement in fundamentals, provides a view of the cross-sectional movements in the market. Indeed, given the reasonable assumption that a market's beta varies over time, one can detect cross-sectional variability in market returns based on the clustering or dispersion of shares' betas. Thus, any change to the volatility of the returns series is captured along with movements in beta. Hwang and Salmon (2001) show that their measure of herding behaviour reflects intentional herding rather than spurious herding (defined below) by isolating movements in beta rather than movements in share returns. The examination of herding behaviour in any financial market (much less an emerging one in the case of South Africa), provides significant insight into the debate on market efficiency. The use of a time-varying beta in detecting herding behaviour offers a stark contrast to the traditional constant beta used in the CAPM. Thus, from the perspective of both the academic and the financial professional, herding behaviour can be a useful indicator in both future market efficiency research and portfolio management strategies. The remainder of this paper is structured as follows: Section 2 provides an overview of current literature, Section 3 presents the methodology used, Section 4 the results, and Section 5 concludes.

\section{Literature Review}

Defining herding behavior: "Men nearly always follow the tracks of others and proceed in their affairs by imitation..." 3 Parker and Prechter (2005) provide an integrated review of the concept of herding behaviour. According to the authors, herding has underpinnings in various disciplines - such as social psychology, information theory, econophysics and ethnology. Each "theory" of herding behaviour makes assumptions about the investor and the market. Shiller (1984) provides the earliest representation of social psychology in financial markets. He presents an alternative share valuation model which includes a factor for investor optimism (pessimism). In developing this model, Shiller (1984) posits that herding behaviour can be detected through asset returns - "The high demand for the asset is generated by the public memory of high past returns, and the optimism those high returns generate for the future" (Shiller, 2001, p.3). From a psychological perspective, herding can be seen as the decision of individuals to follow the group consensus, even when those individuals do not agree with the consensus. In financial markets, this is characterised by investors who suppress their beliefs and information to base their investment decisions on the collective action of the market. This would imply that individual share returns, in the presence of herding, would not deviate significantly from the market return (Christie and Huang, 1995).

Herd Behaviour: Herding behaviour has been examined in many financial markets, with mostly the same conclusions. Of these studies, three popular measures are used to examine herding. Christie and Huang (1995) examine the dispersion of returns during periods of market stress. If market participants follow the crowd, one would expect there to be a low dispersion of a share's return, as their herding behaviour would be captured by share price movements. Intuitively, herding would be more prominent during unexpected and unusual market movements which cause prices to deviate from their averages ${ }^{4}$. They define two measures of dispersion and test them on daily and monthly return data. Daily data often contains too much noise and thus does not provide an accurate result. Using a lower frequency of data controls the element of insignificant fluctuations. Results using monthly data showed a considerably higher magnitude in dispersion (though not an implication of significance), which was attributed to the greater opportunity for individual returns to deviate from the mean return. During periods of market stress, investors tend to become more emotional, and thus can be expected to deviate from rational behaviour. If, during periods of market stress, dispersions of return are low relative to the average return, it is an indication of herding behaviour. Rational asset pricing models (such as the Capital Asset Pricing Model) predict that during periods of market stress, dispersion would increase. Individual assets (shares) will vary in their sensitivity to the market and would thus, during periods of market stress, collectively have returns that would be highly dispersed (possibly due to attempts at diversification). Therefore, herding behaviour offers contrasting predictions to that of rational asset pricing models. In their study of

\footnotetext{
${ }^{3}$ Niccollo Machiavelli, The Prince, Ch. 6, 1514

${ }^{4}$ This deviation could be fundamental in nature and is thus a caveat of this measure.
} 
listed firms in the United States during 1925 to 1988, Christie and Huang (1995) found that herding was absent.

Chang et al. (2000) extend the work of Christie and Huang (1995) by proposing a nonlinear test for herding in international markets. The model developed by Christie and Huang (1995) offers a linearly increasing relationship between the returns and equity dispersion. Chang et al. (2000) propose that the above relationship may be non-linear and that asymmetries may exist with herding during bull and bear markets. They find herding to be present in Taiwan and South Korea (emerging markets) but absent in the United States, Japan and Hong Kong. They also note that in all five of the markets studied, the rate of dispersion increase is higher in bull markets than in bear markets. Investors behave as predicted by rational asset pricing models (shown by an increase in dispersion) in bull markets yet appear to herd (a decrease in dispersion) in bear markets. This result was in line with previous studies that documented an asymmetry in reaction to macroeconomic news. Their results were robust when measured across market capitalisation. Hwang and Salmon (2001) introduce a new measure of herding that looks at the dispersion of a share's beta relative to the market beta. This measure focuses on the risk-return relationship rather than the cross section variation of returns. It improves on the above methods, as in a linear and nonlinear model, a significant cross sectional variation might not necessarily indicate irrational pricing but rather a fundamental change of other factors. By incorporating beta, the cross sectional variability of beta can be interpreted in terms of irrational pricing due to herding or sentiment. This measure captures market wide biases (as opposed to individual biases) which arise from systematic risk. Following a similar line of reasoning as described above, if investors follow the collective market consensus, the dispersion of a share's beta will be lower. Thus, a lower dispersion of beta indicates herding. A share's beta can be affected by either the share's fundamentals or market movements.

The authors argue that "the degree of dispersion in beta over time is not expected to change in response to either idiosyncratic news or share fundamentals" (Hwang and Salmon, 2001, p.6). Their findings show that herding is present (at a relatively lower degree) in the United States, United Kingdom, and (at a relatively higher degree) in South Korea during the Asian and Russian financial crises of 1997 and 1998, respectively. Herding in developed markets is not as prominent as in emerging markets. This could be due to the larger information asymmetry present in emerging markets. They also find that herding is greater before a crisis and becomes relatively weaker once the crisis appears - investors appear to lose confidence in the market once a crisis appears. Using multifactor models, the authors found that during a crisis, investors tend to focus more on value rather than growth shares and size plays a significant role as well. Our study is similar in spirit to that of Caparelli, D'Arcangelis and Cassuto (2004). Caparelli et al. (2004) apply the three methods described previously, to the Italian market and find herding to be present in a relative capacity. They note the asymmetry in results between bear and bull markets (bull markets exhibit greater herding of investors). Herding was also robust when measured across the size of a firm. Hwang and Salmon (2004) test their previously derived method (Hwang and Salmon, 2001) for the United States and South Korea. They include exogenous variables (macroeconomic factors) and find that herding cannot be explained by macroeconomic factors. Their study concludes that herding is present in both bull and bear markets in both countries investigated. Tan, Chiang and Nelling (2008) test for herding behaviour in the Shanghai and Shenzhen Stock Exchanges. They use both the linear test by Christie and Huang (1995) and the nonlinear version by Chang, Cheng and Khorana (2000) modified by using trading volume and volatility as alternate independent variables. Tan et al. (2008) find that herding is present within each exchange in both bull and bear markets, though absent between exchanges (there is no cross exchange effect of a share listed on one market affecting the returns dispersion of the same share listed on the other market).

Hachicha, Bouri and Chakroun (2008) introduce a further measure for herding, Dynamic Herding, based on the work of Hwang and Salmon (2001), which circumvents potential criticisms ${ }^{5}$ of the latter authors' model. The method was successfully tested on the Tunisian Stock Exchange. Dynamic herding relies on a GARCH $(1,1)$ specification as a measure of market volatility, as opposed to a constant value used by Hwang and Salmon (2001). Results of this new method show that herding consists of three components a constant term of herding which is present irrespective of market conditions, an 'anticipation' error term of investors, and the lagged value of herding behaviour from a previous period. The method by Hachicha et al. (2008) was not replicated in this study, although its validity is acknowledged. Economou, Kostakis and Phillipas (2010) investigate herding behaviour in four Mediterranean countries (Greece, Italy,

\footnotetext{
${ }^{5}$ Discussed in the Data and Methodology section.
} 
Portugal and Spain). They test for the presence of linear and nonlinear herding and also use trading volume and volatility as alternate independent variables. Herding behaviour was found present in three of the countries only (Greece, Italy and Portugal). Asymmetry in herding between regimes did exist. Herding was stronger in Portugal during bear markets, yet stronger in Greece and Italy during bull markets. Results using trading volume and volatility offer somewhat contrasting conclusions concerning asymmetry in herding but nonetheless prove herding exists. Finally, Hachicha (2010) examines herding in Canada using Dynamic Herding and finds it to be present.

South African Studies: The literature on herding in South Africa is limited. Gilmour and Smit (2002) test for "institutional" herding 6 in the unit trust industry. They find that herding is present for unit trusts at a certain level of volatility. This relationship implies that the greater the volatility, the greater the herding of unit trusts.

\section{Methodology}

Data: Monthly prices for all shares listed on the JSE as well as the All Share Index (ALSI) were obtained for the period 1995 to 2011. Data was source from FinData@Wits ${ }^{7}$ and where appropriate, McGregor BFA. Apart from the financial crisis in 2007, the last reported trough in the market cycle was during 1999. Data was gathered from one year prior for calculation of returns. This sample period provides a sufficient framework to examine the market cycle, especially given the global recession since 2007 (the period under investigation corresponds to a 'complete' market cycle - it includes a peak between two troughs). The use of monthly prices provided a sufficiently large sample and was sufficient for statistical tests involving degrees of freedom. Logarithmic returns were calculated for each share. These returns were used to study herd behavior via the dispersion tests. Share betas were calculated for use in the beta coefficient test.

\section{Herd Behaviour}

Measures of Dispersion: Investors' behaviour can be seen to differ between 'normal' and 'extreme' market phases. During normal phases, their actions can be described as in modern finance theory. Investors would typically follow their own beliefs (not necessarily rational in nature) and would thereby provide a high dispersion in share returns through trading. During extreme phases, however, emotions tend to increase. This could lead many to follow their peers as a form of reassurance. With many investors making the same investment decision, the dispersion of share returns would be low. The Cross Sectional Standard Deviation (CSSD) measures the dispersion (deviation) between a share's return and that of the market. When market returns vary by a wide margin, CSSD increases and herding is absent. The reason for the increase in dispersion is due to investors following different strategies in an attempt to 'beat the market'. A variety of strategies used translates into a high dispersion of returns. If herding behaviour is present, CSSD increases at decreasing rates, and in severe cases, it can also fall. The reason for the slowdown in the increase is that investors may not necessarily herd towards the market portfolio, but instead may choose to herd towards a share or portfolio of shares. Investors would still choose to follow different strategies, but particular strategies might be favoured over others, resulting in dispersion of a lower magnitude. In the severe case, when herding is towards the market portfolio, the deviation of a share's return would be almost indistinguishable from the market return. CSSD, however, can also have low values because of share fundamentals, not only due to herding. A change in a share's fundamentals translates into a change in that share's returns (and thus its dispersion). Further, if many investors make the same decision without intending to do so, CSSD will also be low. This is referred to as spurious herding (as opposed to intentional herding) and is explained later.

Christie and Huang (1995) suggest that during periods of market stress (without distinguishing between a bull and bear market); investors substitute their own beliefs for that of the market consensus. To distinguish between these 'normal' and 'extreme' periods, the measure of dispersion is calculated as:

\footnotetext{
${ }^{6}$ Institutional herding simply refers to herding where the participants are institutions. It is not a separate type of herding.

${ }^{7}$ FinData@Wits is an internal database compiled by the University of the Witwatersrand. It is a comprehensive database of share prices and associated information.
} 


$$
\operatorname{CSSD}_{t}=\sqrt{\frac{\sum_{i=1}^{N}\left(R_{i, t}-R_{m, t}\right)^{2}}{N-1}}
$$

Where $R_{i, t}$ is the return of share $i$ at time $t, R_{m, t}$ is the market (ALSI) return at time $t$. This formula is simply the standard deviation of the share's returns with the market return as a proxy for the average return. A period is defined as 'extreme' if the returns lie in the upper or lower tails of the distribution of returns. Once these 'extreme' periods are found, the following regression is then estimated (using the computed values as the independent variable):

$$
\operatorname{CSSD}_{t}=\alpha+\beta^{L} D_{t}^{L}+\beta^{U} D_{t}^{U}
$$

where $D_{t}^{L}$ and $D_{t}^{U}$ are dummy variables which have the value of 1 if the corresponding return at time $t$ lies within the respective lower (L) or upper (U) tail of the distribution and 0 otherwise. Herding is present if $\beta^{L}$ and $\beta^{u}$ (which represent the coefficients during the lower and upper 'extreme' periods, respectively) are significantly negative. Sometimes this measure can be sensitive to outliers in the data. Christie and Huang (1995) propose an alternate measure to counter this problem, the Cross Sectional Absolute Deviation (CSAD):

$$
\operatorname{CSAD}_{t}=\frac{\sum_{i=1}^{N}\left|R_{i, t}-R_{m, t}\right|}{N}
$$

In Equation $\{1\}$, the differences between the mean are squared and, if the deviations are large, they would be weighted more heavily. With Equation $\{3\}$, the magnitude of the differences would be irrelevant as they would all have equal weighting. Again, Equation $\{2\}$ is regressed with the computed CSAD values instead and the same evaluation criteria apply.

Nonlinearity of herding using CSAD: In the presence of rational asset pricing models (such as the Capital Asset Pricing Model), the relationship between equity return dispersion and market returns is linearly increasing. Chang, Cheng and Khorana (2000) test this relationship to examine if herding behaviour is present (its presence would imply violation of rational pricing models). They argue that if investors follow aggregate market behaviour, disregarding their own investment strategies, then the relationship between equity and market returns will be nonlinear. Thus, the dispersion between equity and market returns can be nonlinearly increasing or even decreasing. If investors are more emotional during periods of market stress, there is a possibility that a survival mentality is prevalent amongst them (such as an "every man for himself" or a "rushing for the door" mentality). Dispersions can thus increase at a decreasing rate, or in severe cases, dispersion would decrease. These both imply that herding is present. Herding may also be present in an asymmetric capacity and thus would need to be examined in Bull (Up) and Bear (Down) markets. To test this hypothesis, the following regressions are estimated, using the ALSI return as the market return:

$$
\begin{aligned}
& \quad \operatorname{CSAD}_{t}^{U p}=\alpha+\gamma_{1}^{U p}\left|R_{m, t}^{U p}\right|+\gamma_{2}^{U p}\left(R_{m, t}^{U p}\right)^{2}+\varepsilon_{t} \text { where } R_{m, t}^{U p}=R_{m, t} \text { if } R_{m, t}>0 \\
& \operatorname{CSAD}_{t}^{\text {Down }}=\alpha+\gamma_{1}^{\text {Down }}\left|R_{m, t}^{\text {Down }}\right|+\gamma_{2}^{\text {Down }}\left(R_{m, t}^{\text {Down }}\right)^{2}+\varepsilon_{t} \\
& \text { where } R_{m, t}^{\text {Down }}=R_{m, t} \text { if } R_{m, t}<0 \\
& \qquad S \operatorname{CSAD_{t}^{All}}=\alpha+\gamma_{1}\left|R_{m, t}\right|+\gamma_{2}\left(R_{m, t}\right)^{2}+\alpha D_{i}+\gamma_{1}\left|R_{m, t}\right| D_{i}+\gamma_{2}\left(R_{m, t}\right)^{2} D_{i}+\varepsilon_{t}
\end{aligned}
$$

where $D_{i}$ is a dummy variable with the value of 1 , if $R_{m, t}>0$ and 0 otherwise. The values for the independent variable in Equations $\{4\}$ and $\{5\}$ are the corresponding values at time $t$ associated with the selection criteria of the respective regressions (for example, if the market return at time $t$ is positive, then both it and the associated CSAD value at time $t$, are used in Equation \{4\}). Thus, Equation $\{6\}$ would constitute the addition of Equations $\{4\}$ and $\{5\}$. The use of absolute values allows comparisons of the nonlinear term in the above regressions, as well focuses on the magnitude of the return, and not its sign. If investors do herd, a nonlinear relationship between CSAD and the market return would result in a significantly negative $\gamma_{2}^{U p}$ and $\gamma_{2}^{\text {Down }}$ term (these particular coefficients give rise to nonlinearity in the measure and as discussed, they both need to be negatively correlated with CSAD to enable CSAD to decrease when market returns increase). If both these coefficients are significantly negative, it may, however, indicate the presence of a nonlinear rational asset pricing model and not necessarily herding behaviour.

Intentional and Spurious Herding: Spurious herding is defined as behaviour by investors who make the same decision based on the same information at the same period of time. This type of herding is 
inadvertent on the part of the investor. Intentional behaviour, on the other hand, is seen as imitative behaviour - investors deliberately copy each other (or the aggregate market) with blatant neglect of information in their possession. Hwang and Salmon (2001) argue that herding behaviour can be observed in both extreme and normal market conditions. Their method, in contrast to the above, separates intentional and spurious herding and reports only the former. Thus, the method by Hwang and Salmon (2001) is preferred to those previously discussed as it is a more accurate depiction of whether herding behaviour is present. The concept behind their method is that herding may be present in the market between market phases (such as a bull or bear phase) - in other words, at a relative degree. This procedure, although relatively simpler, does have its limitations. It relies on beta as a measure of systematic risk, and assumes variance is stationary (hence the subsequent development of Dynamic Herding by Hachicha et al. (2008)). The authors estimate herding towards the market as:

$$
H(m, t)=\operatorname{var}\left(\frac{\beta_{i, t}-1}{\sqrt{s_{i}^{2} s_{m}}}\right)
$$

where $\beta_{i, t}$ is the beta of share $i$ at time $t, s_{i}^{2}$ and $s_{m}$ are the variance of share $i$ and the standard deviation of the market respectively. This measure can be modified to measure herding toward a factor (other than the market) by replacing the market standard deviation with the factor's standard deviation. So, for example, one can test for herding towards the technology sector. Note that the above measure relates to herding of the market (or simply, aggregate investor behaviour). To calculate the above measure, the following procedure was carried out:

- Estimate each share's beta using the previous 12 month's returns and with the ALSI return as the market return. Calculate standard errors and $t$-values (Student's t-test) for each beta. The calculation of the t-values implicitly represents the fraction in the above formula. For this study, the first estimate was for the period February 1998 to January 1999.

- Repeat the above step using a rolling window procedure - eliminate the return 12 months ago and add the return for the last month (for example, the next estimate would be for March 1998 to February 1999).

- Eliminate insignificant values and determine values for $H(m, t)$ by the variance of the remaining tvalues.

Intentional herding is present if there are significant variations in the cross sectional variance of betas that are not explained by that share's fundamentals. The interpretation of this relative measure of herding is in contrast to the two absolute measures discussed previously - a decrease (increase) in CSSD or CSAD indicates (no) herding. If $H(m, t)$ increases (relative to its previous value), then share betas vary significantly from 1 (market beta) and returns are highly dispersed around the market return. This high dispersion indicates intentional herding. If $H(m, t)$ decreases (relative to its previous value), share betas are not significantly different from the market beta and returns are concentrated around the market return, indicative of no intentional herding. Any fluctuations in $H(m, t)$ may simply represent normal market adjustments implying that returns would tend toward the market return in the long run. To determine if a value of $H(m, t)$ is significant, it is examined in relation to the confidence interval constructed for the $H(m, t)$ series. In summary, by examining a graph of the series, any value that lies outside the confidence interval or any sharp increases in $H(m, t)$ is indicative of intentional herding. Application of these three methods of herding may present contrasting results. In light of this, $H(m, t)$ is used in joint investigations of herding behaviour and nonlinearity in share prices.

\section{Results}

Herd Behavior-Tests using CSSD: Confidence Limits (66\%, 95\%, 99\%) were calculated for the sample and were used to determine if each observation lay within the upper and lower bounds. This procedure is carried out using the JSE Ltd. All Share Index (ALSI) and the arithmetic average return from listed shares. Table 1 shows these results. This step is necessary to enable Equation $\{2\}$ to be estimated. In the $95 \%$ and 99\% confidence levels case of both the ALSI and sample return, all observations lie within the right tail. Results that follow from this tend to be biased as they are indistinguishable from the intercept term when estimating Equation $\{2\}$.

\footnotetext{
${ }^{8}$ The overlapping beta's thus provides us with a graph of their trend through time - which is exactly the objective set out to investigate.
} 
Table 1: Calculated Limits and Frequency

\begin{tabular}{|c|c|c|c|c|c|c|}
\hline & \multicolumn{2}{|l|}{ Limits } & \multicolumn{2}{|c|}{ ALSI return } & \multicolumn{2}{|c|}{ Sample return } \\
\hline $\begin{array}{l}\text { Confidence } \\
\text { Levels }\end{array}$ & Down & Up & $\begin{array}{l}\text { Frequency } \\
\text { "Down" }\end{array}$ & $\begin{array}{l}\text { Frequency } \\
\text { "Up" }\end{array}$ & $\begin{array}{l}\text { Frequency } \\
\text { "Down" }\end{array}$ & $\begin{array}{l}\text { Frequency } \\
\text { "Up" }\end{array}$ \\
\hline $66 \%$ & -0.1142 & 0.0946 & $\begin{array}{l}193 \\
{[5]}\end{array}$ & $\begin{array}{l}186 \\
{[12]}\end{array}$ & $\begin{array}{l}192 \\
{[6]}\end{array}$ & $\begin{array}{l}184 \\
{[14]}\end{array}$ \\
\hline $95 \%$ & -0.2186 & 0.1991 & $\begin{array}{l}197 \\
{[1]}\end{array}$ & $\begin{array}{l}198 \\
{[0]}\end{array}$ & $\begin{array}{l}192 \\
{[6]}\end{array}$ & $\begin{array}{l}198 \\
{[0]}\end{array}$ \\
\hline $99 \%$ & -0.3231 & 0.3035 & $\begin{array}{l}197 \\
{[1]}\end{array}$ & $\begin{array}{l}198 \\
{[0]}\end{array}$ & $\begin{array}{l}197 \\
{[1]}\end{array}$ & $\begin{array}{l}198 \\
{[0]}\end{array}$ \\
\hline
\end{tabular}

Note: If return is inside left tail, $D_{t}{ }^{L}=1$, outside left tail, $D_{t}{ }^{L}=0$. If return is inside right tail, $D_{t}{ }^{U}=1$, outside right tail, $\mathrm{D}_{\mathrm{t}}^{\mathrm{U}}=0$. Numbers reported in square parentheses are the frequency of observations that are outside the respective tail.

Table 2 presents the results for Equation $\{2\}$. Using the ALSI confidence levels, they show that the coefficient of $\beta^{\mathrm{L}}$ is negative in the case of the $66 \%$ confidence level, and statistically insignificant at all levels. However, the coefficient of $\beta^{u}$ is statistically significant, although negative, at the $66 \%$ confidence level. Using the sample confidence levels, the results are somewhat different. The coefficients of $\beta^{\mathrm{L}}$ are negative and significant at all levels. All coefficients of $\beta^{\mathrm{u}}$ are statistically insignificant at all confidence levels, while the intercept term is significant at all confidence levels. The hypothesis of herding behaviour is thus refuted in the absolute sense (in other words, herding is not present overall), yet it should be noted that herding behaviour appears to be asymmetric - it is more significant in the down market phases than up market phases. The asymmetry may be due to a loss in investor confidence (possibly a loss in their own rational analysis) during bear markets. Investors may be tempted to follow the consensus in the presence of bleak outcomes.

Table 2: CSSD Results with ALSI and Sample

\begin{tabular}{|c|c|c|c|c|c|c|c|c|}
\hline \multicolumn{9}{|c|}{ Using ALSI } \\
\hline \multicolumn{3}{|c|}{$66 \%$ Confidence } & \multicolumn{3}{|c|}{ 95\% Confidence } & \multicolumn{3}{|c|}{ 99\% Confidence } \\
\hline$\alpha$ & $\beta^{\mathbf{L}}$ & $\beta^{u}$ & $\alpha$ & $\beta^{\mathbf{L}}$ & $\beta^{u}$ & $\alpha$ & $\beta^{\mathbf{L}}$ & $\beta^{u}$ \\
\hline $\begin{array}{l}0.5614^{*} \\
(5.79)\end{array}$ & $\begin{array}{l}-0.0569 \\
(-0.67)\end{array}$ & $\begin{array}{l}-0.1650^{*} \\
(-3.26)\end{array}$ & $\begin{array}{l}0.3403 \\
(1.52)\end{array}$ & $\begin{array}{l}0.0188 \\
(0.08)\end{array}$ & $\begin{array}{l}0 \\
(\mathrm{~N} / \mathrm{A})\end{array}$ & $\begin{array}{l}0.3403 \\
(1.52)\end{array}$ & $\begin{array}{l}0.0188 \\
(0.08)\end{array}$ & $\begin{array}{l}0 \\
(\mathrm{~N} / \mathrm{A})\end{array}$ \\
\hline \multicolumn{9}{|c|}{ Using Sample } \\
\hline \multicolumn{3}{|c|}{$66 \%$ Confidence } & \multicolumn{3}{|c|}{$95 \%$ Confidence } & \multicolumn{3}{|c|}{ 99\% Confidence } \\
\hline$\alpha$ & $\beta^{\mathrm{L}}$ & $\beta^{u}$ & $\alpha$ & $\beta^{\mathrm{L}}$ & $\beta^{u}$ & $\alpha$ & $\beta \mathrm{L}$ & $\beta^{u}$ \\
\hline $\begin{array}{l}0.7550^{*} \\
(8.83)\end{array}$ & $\begin{array}{l}-0.3484^{*} \\
(-5.08)\end{array}$ & $\begin{array}{l}-0.0713 \\
(-1.33)\end{array}$ & $\begin{array}{l}1.7866^{*} \\
(8.00)\end{array}$ & $\begin{array}{l}-1.3043^{*} \\
(-10.08)\end{array}$ & $\begin{array}{l}-0.1371 \\
(-0.75)\end{array}$ & $\begin{array}{l}1.6495^{*} \\
(12.82)\end{array}$ & $\begin{array}{l}-1.3036^{*} \\
(-10.08)\end{array}$ & $\begin{array}{l}0 \\
(\mathrm{~N} / \mathrm{A})\end{array}$ \\
\hline
\end{tabular}

Note: Coefficient of student's t-test (2 tail) reported in parentheses. ${ }^{*}$ Denotes significance at the $5 \%$ level.

Tests using CSAD: When the measure of dispersion is changed to CSAD, results in Table 3 show that the intercept term is significant in all regressions, indicating that the current variables used are insufficient in explaining CSAD. It is found that the coefficient in down market phases appears to be significant at all levels, using the sample. Based on these findings, and the caveat expressed previously, it is further validated that herding behaviour is present in extreme market phases, again more so in down market phases than up market phases.

Table 3: CSAD

\begin{tabular}{|c|c|c|c|c|c|c|c|c|}
\hline \multicolumn{9}{|c|}{ Using ALSI } \\
\hline \multicolumn{3}{|c|}{$66 \%$ Confidence } & \multicolumn{3}{|c|}{ 95\% Confidence } & \multicolumn{3}{|c|}{ 99\% Confidence } \\
\hline$\alpha$ & $\beta^{\mathbf{L}}$ & $\beta^{u}$ & $\alpha$ & $\beta^{\mathbf{L}}$ & $\beta^{\mathbf{u}}$ & $\alpha$ & $\beta^{\mathbf{L}}$ & $\beta^{\mathbf{u}}$ \\
\hline $\begin{array}{l}0.3109^{*} \\
(5.17)\end{array}$ & $\begin{array}{l}-0.0659 \\
(-1.30)\end{array}$ & $\begin{array}{l}-0.0149^{*} \\
(-4.47)\end{array}$ & $\begin{array}{l}0.2903^{*} \\
(2.49)\end{array}$ & $\begin{array}{l}-0.1846 \\
(-1.58)\end{array}$ & $\begin{array}{l}0 \\
(\mathrm{~N} / \mathrm{A})\end{array}$ & $\begin{array}{l}0.2903^{*} \\
(2.49)\end{array}$ & $\begin{array}{l}-0.1846 \\
(-1.58)\end{array}$ & $\begin{array}{l}0 \\
(\mathrm{~N} / \mathrm{A})\end{array}$ \\
\hline \multicolumn{9}{|c|}{ Using Sample } \\
\hline \multicolumn{3}{|c|}{$66 \%$ Confidence } & \multicolumn{3}{|c|}{$95 \%$ Confidence } & \multicolumn{3}{|c|}{ 99\% Confidence } \\
\hline$\alpha$ & $\beta^{L}$ & $\beta^{u}$ & $\alpha$ & $\beta^{\mathrm{L}}$ & $\beta^{u}$ & $\alpha$ & $\beta^{\mathrm{L}}$ & $\beta^{u}$ \\
\hline $\begin{array}{l}0.5056^{*} \\
(10.14)\end{array}$ & $\begin{array}{l}-0.3381^{*} \\
(-8.07)\end{array}$ & $\begin{array}{l}-0.0766^{*} \\
(-2.73)\end{array}$ & $\begin{array}{l}0.9628^{*} \\
(17.21)\end{array}$ & $\begin{array}{l}-0.8649 * \\
(-15.38)\end{array}$ & $\begin{array}{l}0 \\
\mathrm{~N} / \mathrm{A}\end{array}$ & $\begin{array}{l}1.6353^{*} \\
(38.23)\end{array}$ & $\begin{array}{l}-1.5365^{*} \\
(-35.83)\end{array}$ & $\begin{array}{l}0 \\
(\mathrm{~N} / \mathrm{A})\end{array}$ \\
\hline
\end{tabular}

Note: Coefficient of Student's t-test ( 2 tail) reported in parentheses. ${ }^{*}$ Denotes significance at the $5 \%$ level. Application of Equations $\{4\}$ to $\{6\}$ yield results shown in Table 4. The intercept term is positive and significant for both models. The coefficient of $\gamma_{1}$ is negative and insignificant for both models. The coefficient, $\gamma_{2}$, is of the incorrect sign (it is positive) yet significant in bear market model, a surprising find. 
This would imply that returns during a bear market are not a linear function of dispersion. By the Wald Test $^{9}$, it is found that the difference between the $\gamma_{1}$ terms (the $F 1$ statistic in Table 4 ) as well as the difference between the $\gamma_{2}$ terms of both models (the F2 statistic) is insignificant. However, the significant $\gamma_{2}$ of the bear model indicates that the reaction to news is greater when the market is down (investors reaction to negative news is greater and is not necessarily an indicator of herding), and is shown by a CSAD value lower than the average. By a statistically significant $\gamma_{2}$, herding is adjudged to be present in bear markets (in the absolute sense) and absent in bull markets. This is in line with previous results of this study (namely those of the CSSD measure).

Table 4: Results of tests on nonlinearity in herding

\begin{tabular}{lllllll}
\hline & & & & \multicolumn{3}{c}{ Statistics (p-values) } \\
& $\boldsymbol{\alpha}$ & $\boldsymbol{\gamma}_{\mathbf{1}}$ & $\boldsymbol{\gamma}_{\mathbf{2}}$ & Adj R & $\mathbf{F 1}$ & \multicolumn{1}{c}{$\mathbf{F 2}$} \\
\hline Overall & & & & & 0.98 & 0.50 \\
Bear & $0.0937^{*}$ & -0.0395 & $1.5242^{*}$ & 0.26 & & \\
& $(13.66)$ & $(-0.21)$ & $(2.38)$ & & & \\
Bull & $0.0922^{*}$ & -0.0606 & 6.3569 & 0.01 & & \\
& $(2.47)$ & $(-0.04)$ & $(0.49)$ & & & \\
\hline
\end{tabular}

Note: Coefficient of student's t-test ( 2 tail) reported in parentheses. *Denotes significance at the $5 \%$ level.

The Beta Coefficient Test: Figure 1 presents a graphical representation for the measures of herding using Equation $\{7\}$. Any increase in $H(m, t)$ relative to its previous value, is indicative of herding. Thus, it can be seen that herding was extremely volatile during the period of 1995 to 1998, a possible consequence of international financial crises. Further, $\mathrm{H}(\mathrm{m}, \mathrm{t})$ shows mild volatilility for the period February 1999 to March 2010. The notable exceptions are latter half of 2005 and the middle of 2008. Both these periods have $H(m, t)$ values above the $95 \%$ confidence level, indicative of a possible real-world anomaly. The 2005 period coincides with political instability in South Africa and general risk aversion of investors towards emerging markets. During the latter part of 2008, Lehman Brothers, an investment bank, declared bankruptcy. Both events are depicted by an abrupt increase and subsequent quick decrease in herding during that period. Thus, herding is present in a relative capacity - specifically during periods of instability in financial markets. Similar to Hwang and Salmon (2001), herding appears to decrease once a crisis appears (as seen during the latter halves of 2005 and 2008).

Figure 1: Herding behaviour using the Beta Coefficient Test

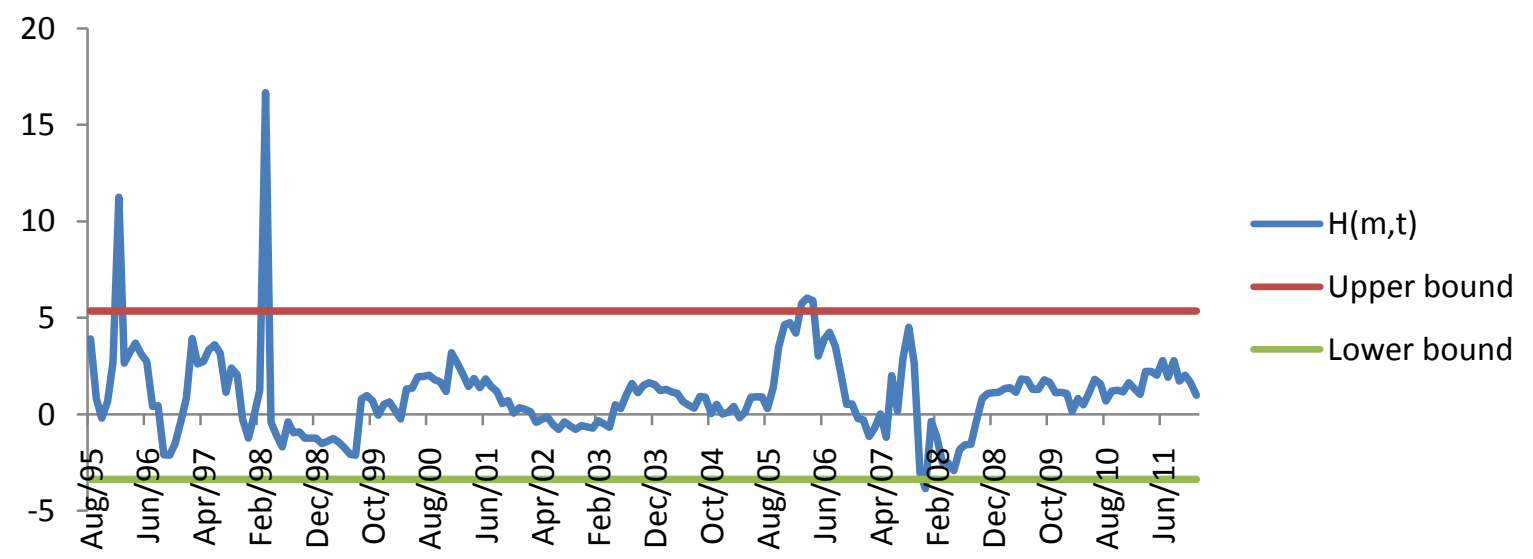

In summary, herding was absent in the absolute sense (overall) and present in the relative sense (during periods of instability). Also, herding during bear markets are stronger compared to during bull markets. Alone, these two results show no linkage. The next question to investigate is whether the relative measure of herding (especially during significant periods) coincides with the asymmetry of herding found during bear markets. Given the absence of herding, the results are in line with Hwang and Salmon (2004). We infer that South Africa would appear to be a developed market as it exhibits a low degree of herding based on an inference from international studies discussed previously where developed markets exhibit low levels of herding.

\footnotetext{
${ }^{9}$ A parametric statistical test used to test the true value of a parameter based on a sample estimate (Wald, 1943).
} 
Bridging the gap: The final step is to find any link between herding behaviour and the performance of the ALSI. From Figure 4, herding behaviour tends to unambiguously increase before contractions of the ALSI. This asymmetry during bear markets is captured by the increase in herd behaviour (relative to its previous value). A Spearman's Rank Correlation test shows that the samples are not independent. Reasons for herding behaviour range from irrationality to protection of reputation. The lag between the increased herding and the proceeding contraction could be explained as follows: Investors perceive themselves to have superior information about future market fluctuations (especially around market crashes). This is fertile ground for herd behaviour to occur as investors would more willingly follow the consensus if they are risk averse - either by nature or due to prevailing negative market conditions (the adage 'better safe than sorry' would apply). Investment decisions made at a point in time may only manifest themselves afterwards, as the market systematically eliminates any potential arbitrage opportunities and also possibly due to hedging strategies that drive down prices of well performing industries. Herding is not as apparent during market expansions. Investors would probably consider themselves either 'safe' or 'superior' during an expansion period. A feeling of safety may lead some to make imprudent decisions and a feeling of superiority would lead some to take unnecessary risk. It would thus be difficult to detect imitation during an expansion.

Figure 2: Herding Behaviour in relation to ALSI movements

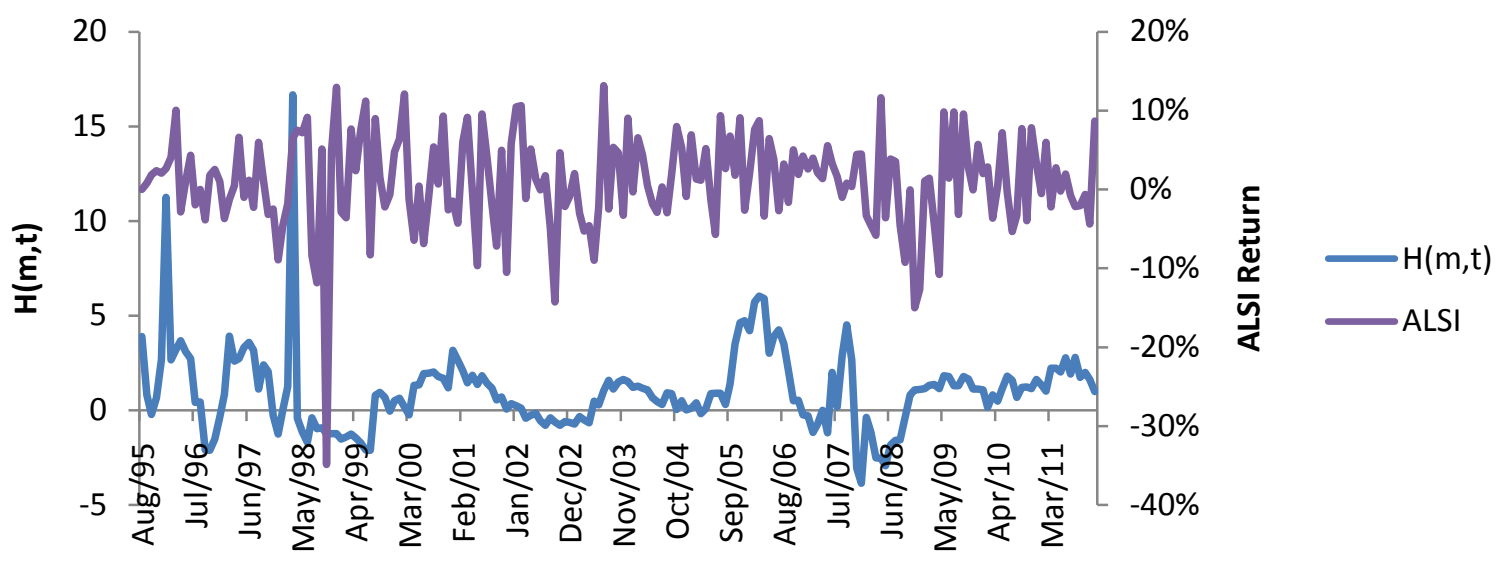

\section{Conclusion}

Several tests of herding behaviour were conducted and herding was found to be present on a relative scale only. Herding was absent in the market overall, yet significantly present in bear markets only. It was further found that herding behaviour appears to increase before a market contraction - the most noteworthy ones being the beginning of 1999 and 2009. These were in line with global economic events. Results were in line with developed economies, indicating the high degree of development in South Africa's financial markets. Herding was prominent before crises and became relatively weaker once the crises appeared, in line with Hwang and Salmon (2001). Potential limitations of the study relate to the biases in data. The data is subject to survivorship bias which could not have been circumvented due to resource constraints. The source the data was gathered from only comprised of those firms that were listed at the time of capture. Thus, data on firms that were listed and subsequently delisted was not available. This could lead to overly optimistic results in favour of herding (as investors would prefer to herd towards a listed firm, as listed firms may be seen to be of a better quality than their non-listed counterparts). Further, the sample size, while not particularly "small", should ideally be larger. Another form of bias, data snooping bias, can be easily levelled against this study. As no macroeconomic factors were used, the results obtained in this study could well be explained by their inclusion (in contrast to that of Hwang and Salmon, 2004). The use of a generated measure of volatility, while more robust, is believed to not enhance the findings of our study. As we have restricted our study to the South African financial market, it follows that we should use historical data in calculating the variation in beta. To make the results of this study applicable in a general context, one can indeed use a variance generated from a timeseries model, such as a GARCH model. Various recommendations for future research can be made. Tests for herding can be conducted using data sets of volume and volatility measures, as opposed to only returns, as used in this study. Another measure, Dynamic Herding, can also be evaluated. This measure, as described earlier, addresses the issue of non-constant volatility in financial markets and could be a more 
accurate measure. Behavioural theories are not often examined in South Africa, possibly due to their complex natures. This paper thus provides a framework for further application of behavioural theories to financial markets in South Africa.

\section{References}

Caparrelli, F., D'Arcangelis, A. M. \& Cassuto, A. (2004). Herding in the Italian Stock Market: A Case of Behavioral Finance. The Journal of Behavioral Finance, 5(4), 222-230.

Chang, E., Cheng, J. \& Khorana, A. (2000). An Examination of Herd Behaviour in Equity Markets: An International Perspective. Journal of Banking and Finance , 24(10), 1651-1679.

Christie, W. \& Huang, R. (1995). Following the Pied Piper: Do Individual Returns Herd around the Market. Financial Analysts Journal , 51(4), 31-37.

Economou, F., Kostakis, A. \& Philippas, N. (2010). An Examination of Herd Behaviour in four Mediterranean Stock Markets. European Economics and Finance Society Conference Paper.

Gilmour, S. \& Smit, E. v. (2002). Institutional Herding: Evidence from the South African unit trust industry. Investment Analysts Journal , 55(1), 21-35.

Hachicha, N. (2010). New View of Herding Behaviour through Trading Volume. Economics E-Journal .

Hachicha, N., Bouri, A. \& Chakroun, H. (2008). Herding Behaviour and Measurement Problems. International Review of Business Research Papers , 160-177.

Hwang, S. \& Salmon, M. (2001). A New Measure of Herding and Empirical Evidence for the US,UK and South Korean Stock Markets. Financial Econometrics Research Centre, 01(12)

Hwang, S. \& Salmon, M. (2004). Market Stress and Herding. Journal of Empirical Finance , 11(4) 585-616.

Lux, T. (1995). Herd Behaviour, Bubbles and Crashes. Economic Journal, 105(43), 881-896.

Parker, W. \& Prechter, J. (2005). Herding: An Interdisciplinary Integrative Review from a Socionomic Perspective. Unpublished.

Shiller, R. (2001). Bubbles, human judgement, and expert opinion. Cowles Foundation Discussion Paper .

Tan, L., Chiang, T., Mason, J. \& Nelling, E. (2008). Herding Behavior in Chinese Stock Markets: An Examination of A and B Shares. Pacific-Basin Finance Journal , 16(1), 61-77.

Wald, A. (1943). Tests of Statistical Hypotheses Concerning Several Parameters When the Number of Observations is Large. Transactions of American Mathematical Society, 54(3), 462-482. 